\title{
OBTENÇÃO DE RELAÇÃO CÊNTRICA EM PRÓTESE FIXA
}

\author{
OBTAINING CENTRIC RELATIONINFIXEDPROSTHESIS
}

\section{Fabrício da Silva', José Boaventura Zumaêta Costaa, Laís Farias Souza ${ }^{3}$, Christiano de Almeida Dultra ${ }^{4}$, Katia Evellyn dos Santos Coutinho ${ }^{5}$}

\begin{abstract}
Autor para correspondência: Fabrício da Silva - fabriciosilva.fs@gmail.com 'Cirurgião-dentista. Feira de Santana, Bahia, Brasil. http://orcid.org/0000-0001-5941-9699 ${ }^{2}$ Dentista especialista em Prótese Dentária. Professor na Universidade Estadual de Feira de Santana. Feira de Santana, Bahia, Brasil. ${ }^{3}$ Cirurgiã-dentista. Feira de Santana, Bahia, Brasil. ${ }^{4}$ Doutor em Prótese Dentária. Professor na Universidade Estadual de Feira de Santana. Feira de Santana, Bahia, Brasil. ${ }^{5}$ Graduanda de Odontologia na Universidade Estadual de Feira de Santana, Bahia, Brasil.
\end{abstract}

RESUMO | Introdução: A obtenção de registros em relação cêntrica $(R C)$, para assegurar uma correta montagem do modelo inferior em relação ao superior, representa uma fase clínica fundamental para o sucesso durante o tratamento em prótese fixa. Objetivos: $O$ presente artigo teve como objetivo fornecer conhecimento, por meio de uma revisão da literatura, sobre a obtenção de RC, sua importância e os métodos de obtenção disponíveis na prática clínica. Métodos: Foram utilizados livros e artigos científicos em bases eletrônicas como ScIELO, Bireme, MedLine e Lilacs, com o principal foco em estudos que relataram diferentes técnicas de registro da relação central. Conclusão: Pode-se concluir ao final deste artigo que a escolha da técnica de registro não é um fator primordial para o cirurgião dentista, e sim a adaptação do profissional e a condição apresentada pelo paciente.

Palavras-chave: Prótese parcial fixa, Oclusão Dentária, Relação Central.

\begin{abstract}
Introduction: Obtaining centric relation records $(R C)$, to ensure a correct setting to the lower dental model in relation to the superior, represents a clinical phase essential for success during treatment in fixed prosthesis. Objectives: The present article is a literature review which objectives to bring up knowledge on Central Relation recording, its importance and different recording techniques available on clinical practice. Methods: Articles found on eletronical resources, such as ScIELO, Bireme, MedLine e Lilacs along with books have been used, focusing on studies about different recording techiniques. Conclusion: Choosing the recording technique is not a primary factor for the dentist, but instead, the professional's acclimation and the patient presented condition.
\end{abstract}

Keywords: Denture partial fixed, Dental Occlusion, Centric Relation. 


\section{INTRODUÇÃO}

A obtenção de registros em relação cêntrica ( $R C)$, para assegurar uma correta montagem do modelo inferior em relação ao superior, representa uma fase clínica fundamental para o uso dos articuladores. A previsibilidade de todos os tipos de tratamento oclusal está diretamente relacionada à capacidade do cirurgião dentista em registrar precisamente a relação cêntrica, já que esta é uma posição chave de referência para análise e reconstrução do sistema mastigatório.

A ausência de uma oclusão equilibrada é um sinal habitual em pacientes desdentados, com perda de unidades dentais e superfícies oclusais ou com mobilidade dental, e deixa $\circ$ profissional com opções muito limitadas e restritas, sendo, desta maneira, o registro de reação cêntrica, ponto fundamental na confecção de próteses. Apesar de ser possível obter o relacionamento interoclusal entre os arcos superior e inferior através de uma simples oclusão dos modelos em máxima intercuspidação é aconselhável montá-los em relação cêntrica, já que, quando corretamente realizada, esta poderá ser usada para futuras análises e como ponto inicial para o estabelecimento de um plano de tratamento.

A RC é uma posição clinicamente determinada da mandíbula na qual ambos os côndilos se encontram na sua posição mais estável em relação a mandíbulal Esta posição se dá quando a relação das maxilas e da mandíbula está de tal maneira que os côndilos posicionam-se o mais centralmente possível dentro das fossas glenóides, sendo ortopedicamente mais estável e tendo os discos articulares adequadamente interpostos. Estabelece-se assim uma situação de maior conforto e estabilidade, que não comprime a zona do epitélio bilaminar, que é por sua vez, ricamente vascularizada e inervada, evitando assim dores e desconfortos. Pressupõese que a partir desta posição obtida seja possível realizar o adequado planejamento, depois dos modelos montados e calibrados em um articulador semi-ajustável(ASA); de uma reabiltação oral e/ou trataras disfunções temporo-mandibulares.

Dawson (1993)' define RC como a relação da mandíbula com a maxila quando o conjunto côndilodisco propriamente alinhado está na posição mais superior contra a eminência, independentemente da posição dos dentes ou dimensão vertical.

Ash $(1996)^{2}$ representa a RC pelo relacionamento entre maxilar superior e mandíbula, no qual os côndilos e discos interarticulares podem estar situados numa posição mais centralizada superior e no interior de cada respectiva cavidade articular.

Shillingburg $(1995)^{3}$ define RC como uma posição que há sustentação ântero-superior ao longo da eminência articular da cavidade glenóide, com - disco articular interposto entre o côndilo e a eminência articular.

A Academy of Dentures Prosthetics $(2005)^{4}$ descreve a RC como:

Relação maxilomandibular em que os côndilos se articulam com a porção avascular mais fina de seus respectivos discos com o complexo na posição superior-anterior contra as formas das eminências articulares. Esta posição é independente do contato dentário.(...) A posição tem de ser definida anatomicamente, mas é determinada clinicamente avaliando-se quando a mandíbula pode articularse em um eixo terminal fixo (até $25 \mathrm{~mm}$ ).

Segundo Cardoso (2003) $)^{5}$, a posição ocupada pelos côndilos na fossa mandibular tem um caráter secundário, pois não existe técnica ideal para confirmá-la.

Pergoraro $(2013)^{6}$ afirma que a relação central $(R C)$, também denominada como RC e, mais recentemente, Posição de Estabilidade Ortopédica, é a relação maxilomandibular marcada pelo posicionamento mais centralizado dos côndilos nas fossas mandibulares, apoiados sobre as vertentes posteriores das eminências articulares e com os discos articulares devidamente interpostos.

$\mathrm{Na}$ literatura, encontram-se inúmeras definições para o termo RC, todavia deve-se escolher a definição que mais satisfaça um conceito clínico. $O$ presente trabalho tem por escopo discutir técnicas de obtenção de RC em prótese fixa através de uma revisão de literatura. 


\section{REVISÃO DA LITERATURA}

Para Fukushima $(2016)^{7}$, há muito poucas controvérsias sobre a oclusão em indivíduos saudáveis, onde a RC é considerada como o critério para avaliar a oclusão presente. Por sua vez, a posição oclusal em pacientes com côndilos remodelados ainda precisa ser esclarecida. Assim, a eficácia e os limites da RC nestes pacientes é variável. Além disso, as posições oclusais induzidas pelo músculo, como a posição postural e as posições terminais de movimentos de fechamento habituais, são sugeridas como substituição da RC.

O importante é que seja encontrada uma posição de intercuspidação estável, onde os movimentos de fechamento habituais terminam sem qualquer contato dentário prematuro.

Thirumurthyet al. $(2013)^{8}$ dão destaque ao teste de carga mastigatória que é feito para verificar se os côndilos estão completamente assentados quando a mandíbula é manipulada suavemente para a posição RC. Um côndilo confortavelmente assentado em posição cêntrica é essencial para qualquer tratamento odontológico. Dawson refere uma RC verificável quando está em harmonia com a posição máxima intercuspidação como condição oclusal Tipo I. Em outras palavras, a oclusão está em harmonia com a montagem do côndilo/disco na articulação temporomandibular. Esta relação é perturbada na presença de interferências oclusais. As interferências oclusais iniciam ações reflexas negativas e alteram - trajeto do movimento mandibular. Isto cria o engrama do músculo (programa neuromuscular) e interfere com o assento completo do côndilo em RC. Dawson refere tal oclusão como uma condição oclusal tipo II. Os contatos oclusais não estão em harmonia com a montagem do côndilo/disco. A desprogramação muscular ou correção oclusal apaga o engrama muscular e permite o fechamento cônico confortável dos côndilos.

Tibiriçá \& Mainieri (1984) realizaram um estudo comparativo entre três técnicas de registro de $\mathrm{RC}$, em pacientes sem problemas oclusais. $O$ instrumento de avaliação das técnicas foi um aparelho denominado Gnatho-thensiometer. As técnicas selecionadas foram: Técnica 1 - Registro de mordida em placa de cera mais parafina refinada com pasta zinco- eugenólica: registros de mordidas foram feitos nestas placas. Tendo pronta a mordida em cera, uma pequena camada da pasta é colocada nas marcas dos dentes de ambos os lados e repete-se 0 fechamento em RC; Técnica 2 - Registro de mordida com cera 7 refinada com pasta zinco-eugenólica utilizando JIG anterior: a mordida é conferida na placa, que possui uma abertura anterior, onde fica localizado o JIG. Conferida a mordida, é aplicada uma camada da pasta sobre a cera e fecha-se a mandíbula em RC; Técnica 3 - Registro com pasta zinco-eugenólica utilizando uma armação metálica (Frame) e gaze: a gaze é presa ao Frame com cera utilidade e coberta com a pasta. A mandíbula é manipulada para $\mathrm{RC}$ e aguarda-se o endurecimento da pasta. Com base nos resultados obtidos, foram possíveis três conclusões: 1) existem diferenças entre as posições de RC alcançadas nas três técnicas; 2) as variações entre as posições de RC ocorreram tridimensionalmente; 3) na técnica de registro com pasta zinco-eugenólica através da moldura de Jones, pode ser considerada a mais precisa, pois houve maior aproximação das faces oclusais. A técnica de escolha deve estar de acordo com as condições em que o paciente se apresenta. Todas as técnicas quando adequadas ao caso e corretamente executadas, podem dar excelentes resultados.

Nishioka \& Bottino $(1987)^{10}$ desenvolveram uma revisão bibliográfica sobre os métodos de obtenção da relação central. A posição de relação central é inteiramente dependente da manipulação do operador. Cada técnica clama por um completo sucesso apesar de resultarem numa posição ligeiramente diferente quando comparadas. Foram descritas quatro técnicas: 1) Método de deglutição ou livre fechamento - técnica onde não existe contato entre o operador e a mandíbula do paciente; 2) Método da manipulação na ponta do queixo - nesta técnica o operador deve colocar o polegar direito sobre o incisivo central inferior do paciente e o dedo indicador sobre o queixo. Sem dor, o profissional deve guiar a mandíbula do paciente a partir da abertura máxima até que ela se assente atrás, na posição estacionária, com o operador trazendo gradualmente os dentes para - fechamento conjunto até que a unha do polegar toque os dentes anteriores superiores; 3 ) Método da manipulação na ponta do queixo com JIG - descrita inicialmente por Vitor $O$. Lucia, que a partir de um plano inclinado adaptado aos incisivos superiores, 
auxiliam os côndilos a assentar-se em sua respectiva fossa e auxilia no registro. O JIG age como um desprogramador do círculo reflexo, portanto, prevenindo o paciente de realizar um fechamento unilateral; 4) Método de manipulação bilateral Dawson modificou os registros com essa técnica onde o paciente deve ficar deitado horizontalmente, com o mento para cima e o pescoço estirado. O operador sentado atrás do paciente, cuja cabeça fica entre o antebraço e a caixa torácica do operador, que com os quatro dedos de cada mão, coloca-os na borda inferior da mandíbula exercendo uma pressão para cima nos côndilos e os polegares colocados sobre a sínfise, cuja carga é aplicada para baixo e para trás. Uma firme pressão será aplicada para manter - eixo condilar para cima firmemente contra os ligamentos limitantes e a eminência. A pressão para trás é aplicada principalmente com os polegares sobre a sínfise conduzindo levemente para baixo; 5) Método Mio-monitor - de acordo com a técnica, esse método eletrônico é designado para gravar os registros oclusais por meio de controle automático involuntário do fechamento mandibular. $O$ eletrodo é inserido próximo a cada inserção mandibular.

O fechamento mandibular é dito ser o resultado de contrações musculares, podendo ser hipotético que o espasmo deflete a mandíbula por meio da interrupção da intercuspidação do dente.

Araújo et al $(1988)^{11}$ realizaram um estudo comparativo de duas metodologias para registro da relação central. Para realização dos experimentos foram selecionados 15 pacientes que apresentaram dentição íntegra até no mínimo segundos molares, ausência de trabalhos protéticos e nenhum sinal de disfunção mandibular. A técnica do JIG obedece à orientação do texto de Lucia que preconiza uma superfície plana menor possível em contato com um dos incisivos centrais. O JIG é ajustado na dimensão vertical mais próxima possível da DVO (dimensão vertical de oclusão) e um registro de cera é obtido com o dispositivo através da técnica de manipulação bilateral de Dawson, sem pressão muscular por parte do paciente. A outra técnica utilizada, a de Long, utiliza um calibrador de tiras de acetato, aproximadamente 20, cortadas de filme radiográfico com $60 \mathrm{~mm}$ de comprimento, $8 \mathrm{~mm}$ de largura e $0,35 \mathrm{~mm}$, em media, de espessura. Introduzem-se as fitas uma a uma entre os incisivos centrais (superior e inferior) do paciente até que não haja toque de nenhum dente posterior, que é verificado com papel celofane. Nesta dimensão vertical então, manipula-se o paciente em $\mathrm{RC}$ pela técnica de Dawson e faz-se um registro de cera com o dispositivo interposto. Os registros foram comparados por três métodos distintos: conferencia do primeiro contato prematuro, preensão da fita de celofane entre os dentes posteriores e análise milimétrica horizontal. Com base no presente estudo, o dispositivo de Long deve ser usado clinicamente para as tomadas de $\mathrm{RC}$, para análises oclusais funcionais, planejamento de casos clínicos e exames de pacientes com dor associada a ATM, sendo um método simples e mais rápido que o JIG, demandando porém, experiência e domínio da técnica de manipulação da mandíbula em RC.

Para Avinash et al. $(2014)^{12}$, a reabilitação em casos de atrição extrema, frente ao bruxismo, usando o conceito de estágios duplo de $\mathrm{HOBO}$, é feita através do uso de um desprogramador oclusal para o estabelecimento da RC, e, conseguinte montagem dos modelos no articulador semi-ajustável. Daí então, é realizado oenceramento posterior, em uma etapa, e o anterior, em outra, quando será estabelecida a guia incisal.

Souza $(1993)^{13}$ realizou um estudo comparativo de quatro técnicas para registro de RC. Foram selecionados 10 pacientes adultos em bom estado de saúde sistêmica e bucal, todos estudantes da FOUERJ. As quatro técnicas utilizadas foram: 1) Técnica de manipulação unimanual (Ramfjord e Ash); 2) Técnica da manipulação bimanual (Dawson); 3) Técnica do JIG (Lucia); 4) Técnica de calibrador (Long). Na maioria dos casos não houve diferença estatisticamente entre as técnicas. A técnica unimanual apresentou resultados mais consistentes, sendo mais uniforme, com médias menores na análise estatística. A técnica do JIG apresentou em 3 variantes, diferença estatisticamente significativa. No trabalho, não foram encontrados argumentos suficientes para estabelecer a técnica ideal para todos os casos. Outros estudos devem ser feitos para avaliação de variáveis que podem ser incorporadas às técnicas, interferindo nos resultados.

Rívera \& Dias $(1999)^{14}$ analisaram 0 uso do desprogramador anterior modificado no registro 
da Relação Central. Foi confeccionado um desprogramador com acrílico auto-polimerizável seguindo as indicações de Lucia. Indicou-se o uso do dispositivodurante três horas antes do registro da RC. Em um gral de borracha com água à $60^{\circ} \mathrm{C}$, se molda a godiva em forma de cubos de $1 \mathrm{~cm}$ para serem usados no registro de RC. Os cubos foram colocados nas faces vestibulares de pré-molares e molares e foi pedido que 0 paciente ocluísse. Após o registro, os blocos são retirados da boca, removidos os excessos e procede-se à montagem do articulador. $O$ uso do desprogramador anterior modificado permite que a mandíbula assuma uma posição mais estável e confortável para registro da RC. O uso desta técnica permitirá um assentamento mais completo e estável das posições músculoesqueléticas.

Dekon, Barbosa e Mariano (2002) $)^{15}$ compararam, através da análise de casos clínicos, a precisão da transferência da posição de RC em modelos de gesso montados em articuladores semiajustáveis, comparando duas técnicas de registro intermaxilares. Foram selecionados pacientes de acordo com alguns critérios para garantir ausência de grandes distúrbios temporomandibulares, Todos os pacientes passaram por um teste anamnético de Disfunção Temporomandibular, sendo quesomente foram utilizados os pacientes considerados com DTM ausente ou do tipo leve. Durante o exame anamnético foi também verificado se $\circ$ paciente realmente possuía diferença entre a posição de $\mathrm{RC}$ e a $\mathrm{MIH}$. Após essas verificações anamnéticas, foi identificado o primeiro toque dentário - a posição de RC - e anotado, afim de precisar o local anatômico onde ocorre este toque. Foram obtidos os modelos e montados em um articulador semi-ajustável, seguindo-se a etapa de obtenção dos registros de RC. Foram utilizadas duas técnicas de obtenção de registros de RC. 1) Técnica de Manipulação Bilateral, associada à utilização de J.I.G. 2) Utilização de "Leafe Gauge", confeccionada através de fitas de acetato com as seguintes medidas: $60 \mathrm{~mm}$ de comprimento, $8 \mathrm{~mm}$ de largura e $0,355 \mathrm{~mm}$ de espessura. Os resultados encontrados neste experimento mostraram variações milimétricas entre 0,5 e 2,3mm para as posições estudadas, tanto no lado direito quanto no lado esquerdo, no plano sagital. Já no plano horizontal, tais variações ficaram entre 2,8 e 4,8mm. A análise não mostrou diferenças estatisticamente significantes entre as técnicas, tanto no plano sagital quanto no plano horizontal.

Para Thakur et al. $(2014)^{16}$ as técnicas de estabelecimento da RC mais funcionais serão preferidas frente àquelas técnicas impositivas, ou seja, estáticas. O método estático de estabelecimento da RC parece mais ineficiente que os métodos dinâmicos ou funcionais.

\section{CONCLUSÃO}

Conceituar a Relação Cêntrica, obter e registrá-la sempre foi um desafio para o cirurgião-dentista. Mas pode-se afirmar, a partir dessa revisão de literatura, que diversos autores definem a RC como uma posição "ideal" entre o côndilo e a fossa mandibular (superfície articular do osso temporal). A obtenção e registro da $\mathrm{RC}$ são passos importantes para o sucesso do tratamento no contexto da reabilitação oral com prótese parcial fixa, e traz maior conforto e estabilidade oclusal para o paciente.

Há que se atentar para a perfeita distinção daquela RC trazida pela Antiga Escola Gnatológica em que faz referência a posições do côndilo idealizadas,para uma condição clínica de assunção de uma posição ortopedicamente estável, com vantagens terapêuticas. Este aspecto pode diferenciar aqueles pacientes sintomáticos dos assintomáticos o que pode dar oportunidade da obtenção de posições cada vez mais estáveis.

Os diferentes métodos apresentam seus níveis de acuidade e segurança, e estão devidamente embasados na literatura correspondente. Desta forma, cabe ao cirurgião-dentista conhecer as possíveis técnicas de registros, seus pormenores e características, de maneira a conseguir adequá-las da melhor forma às condições apresentadas pelo paciente. 


\section{CONFLITOS DE INTERESSES}

Nenhum conflito financeiro, legal ou político envolvendo terceiros (governo, empresas e fundações privadas, etc.) foi declarado para nenhum aspecto do trabalho submetido (incluindo mas não limitandose a subvenções e financiamentos, conselho consultivo, desenho de estudo, preparação de manuscrito, análise estatística, etc).

\section{REFERÊNCIAS}

1. Dawson PE. Problemas oclusais. 2 ed. Rio de Janeiro: Livraria Editora Artes Médicas LTDA; 1993.

2. Ash MM. Oclusão. 4 ed. Rio de Janeiro: Editora Guanabara Koogan S.A; 1996.

3. Shillingburg HTJ, Hobo S, Whitsett LD. Fundamentos de Prótese Fixa. São Paulo: Santos Editora Ltda; 1995.

4. The glossary of prosthodontic terms. J Prosthet Dent. 2005;94(I):10-92.

5. Cardoso AC. Oclusão para você e para mim. São Paulo: Santos; 2003. p.3-6.

6. Pegoraro LF, Valle AL, Araujo CRP, Bonfante G, Conti PCR. Prótese Fixa. Bases para o planejamento em Reabilitação Oral. 2a edição. São Paulo: Artes Médicas; 2013.

7. Fukushima S. A controversy with respect to occlusion. Jpn Dent Sci Rev. 2016;52(3):49-53. doi: 10.1016/i.jdsr.2016.02.001

8. Thirumurthy VR, Bindhoo, Jacob SJ, Kurien A, Limson KS, Vidhiyasagar P. Diagnosis and Management of Occlusal Wear: A Case Report. J Indian Prosthodont Soc. 2013;13(3):366-372. doi: $10.1007 / \mathrm{s} 13191-012-0173-2$

9. Tibiriça MV, Mainieri ET. Relação cêntrica: comparação entre 3 técnicas de registro, Revista Fac. Odontologia Porto Alegre. 1984;23:53-65.

10. Nishioka RS, Bottino MA. Relação central: considerações. Revista Brasileira de Odontologia. 1987;XLIV(2):35-39.

11. Araújo CRP, Pandolfi RF, Bonachela V, Martins FP. Estudo comparativo de duas metodologias para registro da relação cêntrica. Revista Odontol. USP. 1998;2(2):73-76.

12. Avinash CkA, B C, Charry NS, Reddy R, Jaqini AS. Restoring the Lost Functional Harmony in a Mutilated Dentition using Hobo's Twin Stage Concept of Full Mouth Rehabilitation. J Clin Diagn Res. 2014;8(9):21-3. doi: 10.7860/ JCDR/2014/7982.4830

13. Souza HMMR. Estudo comparativo de 4 técnicas para registro de relação cêntrica. Revista Bras. Odontologia. 1993;50(5):16-20.
14. Riviera E, Diaz A. Uso del Deprogramador Anterior modificado en el Registro de la Relación Céntrica. Revista Estomatol. Herediana. 1999;9(1-2):42-46.

15. Dekon, SFC, Barbosa ALP, Mariano RQ. Comparative study of different methods and materials employed in the centric relation record in dentulous patients. JBA. 2002;2(5):48-53.

16. Thakur M, Jain V, Parkash H, Kumar P. A comparative evaluation of static and functional methods for recording centric relation and condylar guidance: a clinical study. J Indian Prosthodont Soc. 2012;12(3):175-81. doi: 10.1007/s13191012-0154-5 